\title{
Does Foreign Direct Investment Improve Inclusive Green Growth? Empirical Evidence from China
}

\author{
Nanyue Wang: The Chinese University of Hong Kong, China.
}

\begin{abstract}
The main aim of the study was based on whether the foreign direct investment improves inclusive green growth in case of empirical evidence from China. In order to empirically analyse the association of FDI with the green inclusive growth, the researcher of the study has used secondary quantitative data. The data has been taken from 19812019 from World Bank. The IGG has been computed using Principal Component Analysis (PCA) which has been later used as the independent variable. The data has been considered of the last 30 years with annual frequency. The findings of the study revealed that in long-run, there is no relation between FDI and inclusive green growth. However, based on the short-run results, it can be evaluated that FDI and IGG are related. The paper still has some of the limitation because only China was used for the testing the variable.
\end{abstract}

Key words: Foreign direct investment, Green growth china.

\section{Introduction}

The terminology 'Inclusive Growth' was first used in 2007 by Asian Development Bank and was associated with the national goals of the countries especially, to attain balanced development (Narloch, Kozluk, \& Lloyd, 2016). Simultaneously, the concept of green growth also grabbed the attention of economists and scholars. According to the study of Atewamba and Ngondjeb (2020) the word 'inclusive green growth' was first used in 2012 by the Rio G20 Summit and it underpins both the aspects that are inclusiveness and concept of green where the former is linked with income gap and the latter is associated with the sustainability. The study of Chen, Yang, and Chen (2020) asserted that inclusive green growth integrates social, environmental and economic dimensions. On the other hand, the study of Zhu and Ye (2018) tested the association of foreign direct investment (FDI) with the inclusive green growth presenting the argument that FDI helps to increase the economic progression as the productivity of the host country increases. However, concerning the case of developing nations, they are encountering incongruities between environmental pollution and economic progression. This is resulting in broadening the income gap whereas, managing inclusiveness in developing nations is promoting the social progression as well which is helping to deal with environmental pollution.

Considering the integrated aspects, the underlying question is how a country can strategize its FDI in order to promote inclusive green growth and sustainable development of the country. The research carried out by Zhu and Ye (2018) supported this aspect but in the context of China. Therefore, the gap still remains unaddressed concerning the other developing nations, for instance, China. In accordance with World Bank (2015), the government needs to work alongside the private sectors in China for inclusiveness and sustainability. It has been further reported by the same study that inclusiveness needs to be improved with more investment opportunities for bankable projects. Thus, it can be stated that in the context of China, there

International Journal of Business Management Vol. 3, No. 1, Research

2020 This study received no specific financial support.

Received: 7 April 2020

Accepted: 20 May 2020

Publishing Group 
is no evidence present, therefore, this research intends to fill this gap by aiming to analyse the effect of FDI on the inclusive green growth of China.

\section{Literature Review}

Though the previous literature showed a unique perspective of foreign direct investment (FDI) on the climate, there is also another possibility that foreign direct investment can lead to a greener environment (Eregha \& Mesagan, 2017). Particularly, if FDIs originate from environmentally friendly and greener technologies. It is also evident from the study of Tran (2019) that foreign companies in the under-developing countries are more concerned with environmental protection as compared to the local companies. In research, Zhu and Ye (2018) indicated that the US-based companies in the under-developing countries use greener energy to operate as well as they are energy-effective. The probability that foreign direct investment minimizes the pollution level is too evident in researches, for example, Jha, Sandhu, and Wachirapunyanont (2018) claimed in a study that foreign firms are more concerned with the environment-related matters as they adopt up-to-date technologies and innovation. It is along with the effective management activities which are beneficial for the overall environment in comparison with the domestic ones (Ojha, Pohit, \& Ghosh, 2020).

Several researches have been conducted to clear the ambiguity found in the theoretical constructs of the relationship between foreign direct investment and green economic development (Ojha et al., 2020). Though, these empirical researches in this domain have only increase the ambiguity because the research findings of these studies are contrasting with each other (Eregha \& Mesagan, 2017). Gu, Renwick, and Xue (2018) mentioned that the previous literature is highly based on several case studies. Such cases undertook various countries, pollutants or environmental markers. Various pollutants such as sulphur dioxide, carbon dioxides, suspended particles like smoke, fumes, dust, volatile organic compounds, nitrogen oxides and so on(Eregha \& Mesagan, 2017). Particularly, researches for instance as Sun, Ding, Yang, Yang, and Du (2020) studied carbon dioxide as a pollutant measure. On the other hand, Jha et al. (2018) also take total particles, total toxic emissions and biological oxygen demand. Researches for example, Ojha et al. (2020) noted how foreign direct investments that are foreign-based and China-based influence air and water pollution indicators comprising of dust, waste gas, waste water, sulphur dioxide and petroleum. Likewise, Acosta and Suresh (2016) and Nasir, Huynh, and Tram (2019) use the emissions of sulphur dioxide and carbon dioxide from the industrial sector respectively.

Furthermore, past studies indicated that foreign direct investment are the essential source of any country's economic development. Recently, researches have been undertaken that found the importance of FDI in sustainable development of countries. Zhu and Ye (2018) stated in a study that there is a broad acceptance among the research experts that foreign direct investment facilitates economic development in a specific country by an increased capital formation rate. With the perspective of facilitating economic development foreign direct investment might have an impact on the emission of greenhouse gases, also the findings from these researches performed by other scholars gave mixed findings, yet if taking the concluding figures, it can be noted that in few countries over 40 percent of foreign direct investment lies in industry, there is an effect on the level of greenhouse gas (Eregha \& Mesagan, 2017).

According to research conducted by Gu et al. (2018), most of the firms prioritize their business to the damaging impact of energy rationalization because the latter minimizes costs instead of creating a turnover. From the past years, the studies indicated a shift of foreign direct investment to green energy plans programs, energy effective that has a better environmental impact (Gu et al., 2018). The development of innovations had a substantial effect on multinational firms' location. Many foreign direct investment companies implement innovations and facilitate technological advancements, attaining an improved performance and supporting in developing an economy with low-carbon level. Similarly, Sun et al. (2020) highlighted that this fact is a great initiative as most firms concentrate more and more on the energy effective business systems and activities.

Moreover, multinational firms are the primary contributor to foreign direct investment and by their business functions, they change the host countries' economic environment. According to the research performed by Jha et al. (2018), sufficient strategies and policies might influence inclusive green growth, FDI, and green development problems positively if they were addressed for every economic function particularly. Within this context, scholars observed that the multinational companies facilitate environmentally friendly activities in countries that have weak policies in this domain, due to the fact that their standards for implementation such as ISO 14001 (Berkhout, Bouma, Terzidis, \& Voors, 2018). However, many researches 
demonstrated that effective environmental laws have also been evaluated as effective sources for comparative benefits (Sun et al., 2020).

In a study conducted by Ojha et al. (2020) claimed that the rapid economic development, the ineffective resource location, and its use, high level of environmental pollution and a frequent generation of thick haze and smog in past years have led the governments of both developed and developing countries to transfer from a creative economic development model that includes greater emissions and greater energy consumptions, greater pollution, low emissions and low energy consumption economic development model (Sun et al., 2020). All such prerequisites might have a negative effect on the existing economic development (Eregha \& Mesagan, 2017). Thus, the world economies are rising a question which is: economic development comes first or the environmental safety?

According to Nasir et al. (2019), sustainable investment is considered as domain that has been studies priorly by academicians. Particularly, the main focus was the developing markets. With respect to FDI, the inclusive green growth, though, has been emphasized on the environment. Different other green growth elements influence was incorporated by the green development objectives ultimately. Apart from it, the environmental concerns for inclusive green growth for instance, from a macro-view, some factors are there such as economic and social factors that has to be embedded (Berkhout et al., 2018). Many multinational companies consider these factors in their business operations and they work towards the green development in order to make their sustainable contributions to the overall society. Zhu and Ye (2018) added that sustainable development also helps the companies to improve their brand reputation and their image at a global level.

\section{Theoretical Framework}

Acosta and Suresh (2016) stated that FDI helps in facilitating the economic development within the host countries by improving its ratio of total factor productivity. This theory was broadly claimed. In contrast with past researches, most under-developed countries are experiencing a contradiction among environmental damage and economic development, and the broadening gap in the rate of income (Sun et al., 2020). In contrary to it, in the past years, these underdeveloped countries are more willing to analyze this contradiction (Berkhout et al., 2018). Such as, the poverty alleviation development of India and the inclusive green growth of certain countries are facilitating social development by decreasing the environmental pollution level on closing the gap in the rate of income. Though, the following question is generated: can foreign direct investment improve the inclusive total factor productivity of a certain country and facilitate inclusive green economic growth?

Another emerging theory for inclusive green growth of economy helps in defining the objective of mutual prosperity and poverty reduction and by protecting planetary borders, that include, fresh-water, land, climate and ocean (Sun et al., 2020). This theory generates some particular outcomes and solutions by the change of economic development that is conventionally examined through the balance among how goods or services produced and about their quantity. Inclusive growth theory focuses on gathering a production of new resources, sustainable natural capital such as fisheries, forests, and freshwater, green physical capital such as improved public transport method, wind turbines, solar energy panels, waste recycling/reusing and waste treatment provisions for the betterment of the economy, social capital such as equitable accessibility to social safety floors, social services, social protection nets, and other opportunities to manufacture all goods or services in an eco-friendly way (Berkhout et al., 2018). In addition to it, assuring social and work inclusion (an irrelevant mix which is trade-offs and complementarities in such resources to generate a demanded product needs deep research on a case foundation). In the meantime, to promote the product innovation, the inclusive green model facilitates the shift of trade, consumption, public expense, and investments towards the product or services generated with the new resources' identification (Sun et al., 2020).

This inclusive green economic development model was established in two dimensions: the first one is that some research explains the meaning and connotation of inclusive green growth. According to the study performed by Sun et al. (2020), economic green growth requires inclusive green growth and sustainable development. As highlighted by Ojha et al. (2020), inclusive green growth is an important factor in attaining sustainable growth within the economy. Nasir et al. (2019) and Zhu and Ye (2018) claimed that inclusive green growth is considered an inclusive technique for effective utilization of natural resources. Moreover, for assessing the effect of pollution and various pollutants on the surrounding environment and assure that the development method is inclusive. Nasir et al. (2019) highlighted that inclusive green development must have 
an association between green, inclusive, and growth aspects. Within the whole development process, we are required to assure that the economic betterment of contemporary individuals and not affecting the next generation. According to the research performed by Acosta and Suresh (2016), inclusive green development is highly considered as a sustainable method to promote economic development, better environmental ecology, resource conservation, social equity, result sharing, and so on.

However, several researchers have given different descriptions for inclusive green development from various dimensions (Berkhout et al., 2018). Minimizing the difference in the income rate is its particular essence and ecological problems are the major factors to attain inclusive green growth. According to the study performed by Cwele (2019), in comparison with the green growth, mutual growth and poverty reduction not only needs improvement is the peoples' living as well as economic development. Yet, also requires a boost in environmental effectiveness. Secondly, few researches have measured and described inclusive green growth markers. Gu et al. (2018) stated in a study conducted on inclusive green growth that there is a detailed index. This index was to estimate inclusive green development along with a range of environmental, social, and economic markers and found the effect of a set of different components on the inclusiveness, for example, urbanization, education, construction, and infrastructure (Acosta \& Suresh, 2016).

In relation to the above information, this research examines the effect of foreign direct investment on inclusive green growth based on three factors. Inclusive growth, green technological effectiveness and total factor productivity. Thus, there are some definite contribution by this research which include: this research contributed towards the existing literature by deciding whether foreign direct investment is effective or not in the context of inclusive green growth. By this research, the author gives a primary empirical proof by working in the context of China. Besides that, the primary goal finding whether foreign direct investment has an impact on the surrounding environment, this study also gave a deep knowledge as it analyses whether the impact of foreign direct investment on greenhouse gasses emissions varies for different countries at various developmental stages. This concept is in correspondence with the research of Ojha et al. (2020) that the income rate of the country affects the design of their environmental laws and regulations. Finally, this research also found a distinct point among the impact of foreign direct investment on various pollutants mentioned above. This research also highlighted the differences in the final results. Hence, in this way, the study measured the combined impact of foreign direct investment after finding the related factors within the past available literature.

\subsection{Hypothesis}

An increased flow of foreign direct investment contributes towards a substantial change in the greenhouse gases emissions.

The impact of foreign direct investment on the greenhouse emission level varies substantially among the under-developed and highly developed countries.

\section{Data and Methodology}

The present research is based on the quantitative data where secondary sources have been reviewed for the data collection. In order to empirically analyse the association of FDI with the green inclusive growth, the researcher of the study has used secondary quantitative data. The data has been collected from the World Data Bank concerning the required variables. The dependent variable used in this study if FDI and the independent variable is inclusive green growth (IGG). For the computation of the IGG index, the researcher has used the following variables which are also supported by the study of Chen et al. (2020).

- Net investment in non-financial assets.

International Journal of Business Management and Finance Research Vol. 3, No. 1, pp. 12-19

- Compensation of Employees/ Employment to population ratio.

- Land Area.

- Electricity production.

- GDP per Capita.

- Forest Area.

- $\mathrm{CO} 2$ emission.

- Combustible renewables and waste.

Based on the mentioned variables, the IGG has been computed using Principal Component Analysis (PCA) which has been later used as the independent variable. The data has been considered of the last 30 
years with annual frequency. For the assessment of the association, the researcher has used Autoregressive Distributed Lag Model (ARDL) which is preceded by unit root testing. According to Abdi and Williams (2010) , the large data sets are mainly used for interpreting difficult studies for which Principal Component analysis (PCA) that is regarded as the technique for reduction in the dimensionality for such datasets which increase the interpretability of difficult variables and to avoid information loss. The use of principal component is focused on reducing the eigenvalue and new dataset are explained at hand.

In addition to the above statement, the academic work conducted by Odhiambo (2009) has used autoregressive distributive lags (ARDL) for testing and determining the interrelation between the existences of long-run or short-run impact of the variables. However, the study conducted by Kurecic and Kokotovic (2017), has used VAR for analysing causality in order to determine the unidirectional association between the variables. Moreover, it is also important for stating that ARDL has some prerequisite assumptions which are necessary to meet. In this manner, the selection of the ARDL was entirely based on the premise that it does not require data to be stationary and secondly that ARDL is considered to be most effective way for capturing long-run relation. The ARDL is formulated as,

FDIit $=$ NIit + EPRit + LAit + EPit + GDPit + FAit + CO2it + CRWit

\section{Results and Analysis}

\subsection{Descriptive Statistics}

The Table 1 presented below explains the descriptive statistics of the key variables of the study and it reflects that mean value of LFDI is estimated at 6.49 which can vary positively or negatively with the standard deviation value of 6.78. This mainly implies that there is significant impact of FDI on inclusive green growth in China. Furthermore, the mean Net Investment is estimated at 4.65 with the standard deviation of 3.11 and indicates that inclusive green growth is significantly improved by the FDI in China as FDI here is presented by the natural logarithm. In addition to the above statement, the mean value of the employment which is estimated at 63.59 with the standard deviation of 1.93 implies that due to employment, the inclusive green growth can be improved with the help of FDI in China. Furthermore, the electricity is another component for the IGG where the mean value is estimated at 79.80 with slight standard deviation of 15.19 implying that the electricity consumption might increase or decrease with the improvement of FDI in China.

\begin{tabular}{|c|c|c|c|c|c|}
\hline Variable & Obs & Mean & Std. Dev. & Min & Max \\
\hline LFDI & 39 & 6.498255 & 6.780416 & -9.65805 & 10.30416 \\
\hline Net Investment & 39 & 4.658588 & 3.110935 & 1.166109 & 12.61221 \\
\hline Employment & 39 & 63.59657 & 1.9327 & 59.283 & 67.56 \\
\hline Land Areas (qkm) & 39 & 1811570 & 0 & 1811570 & 1811570 \\
\hline Land Area & 39 & 14.4097 & $1.80 \mathrm{E}-15$ & 14.4097 & 14.4097 \\
\hline Electricity & 39 & 79.80711 & 15.19992 & 48.9 & 98.51 \\
\hline GDP per capita & 39 & 1609.191 & 1286.459 & 442.2155 & 4135.569 \\
\hline LGDPC & 39 & 7.08029 & 0.779553 & 6.091797 & 8.32738 \\
\hline Forest aread & 39 & 767539.5 & 432182.2 & 48.9 & 1185450 \\
\hline LFA & 39 & 11.59562 & 4.097144 & 3.889777 & 13.98563 \\
\hline C02emission & 39 & 1.342133 & 0.502314 & 0.642835 & 2.153758 \\
\hline Combustible & 39 & 31.28726 & 14.46477 & 2.153758 & 52.6769 \\
\hline
\end{tabular}

\subsection{Principal Component Analysis}

The principal component here reflects two panels where the first panel has listed out eigenvalues for the International Journal of Business Management and Finance Research eigenvectors are mainly listed in the secc column wise sum of the squares for the loadings $(5.2708+0.977123+\cdots+0.038361=1)$. The software and the literature which treats principal component with the combination of the factor analysis mainly tends to display the principal components which are normed for the associated eigenvalues rather than 1 . The first principal component has the variance 5.27, explaining 52\% (5.27/7) of the total variance. The second principal component has variance 0.977 or $97 \%(0.977 / 7)$ of the total variance (see Table 2). Hence, the PCA are 
uncorrelated. As a consequence, it can be stated that the first two principal component explains the sum for the variances of the individual components for the total variance.

While observing the data more closely, it can be interpreted that the first component has positive loadings, however, it is not equal in terms of variances of the variables. Moreover, the second principal component also has a positive loading with the average which reflects that this component can be significant for the inclusive green growth. The third component similarly differentiates the inclusivity at 0.22 with respect to other differences. Therefore, except comp1, all components can be taken for the indices of Inclusive Green Growth in China.

Table-2. Principal component analysis.

\begin{tabular}{lllll}
\hline Component & Eigenvalue & Difference & Proportion & Cumulative \\
\hline Comp1 & 5.2708 & 4.29368 & 0.753 & 0.753 \\
Comp2 & 0.977123 & 0.591613 & 0.1396 & 0.8926 \\
Comp3 & 0.38551 & 0.226088 & 0.0551 & 0.9476 \\
Comp4 & 0.159422 & 0.050842 & 0.0228 & 0.9704 \\
Comp5 & 0.108579 & 0.048373 & 0.0155 & 0.9859 \\
Comp6 & 0.060206 & 0.021845 & 0.0086 & 0.9945 \\
Comp7 & 0.038361 & $\cdot$ & 0.0055 & 1 \\
Number of obs & $=\quad 39$ & & & \\
Number of comp & $=7$ & & & \\
Trace & $=\quad 7$ & & & \\
Rho & $=1.0000$ & & & \\
\hline
\end{tabular}

Considering the next Table 3 presented, it can be observed that the first panel is not influenced, whereas, the second panel list two principal components for employment. Moreover, the components listed below do not contain all information in the data and hence some of the variances are unaccounted for or may be unexplained. In addition to the above statement, these equal the sum for the squares of the total loadings within the deleted components that is weighted by associated eigenvalues.

Table-3. Variable Panel of the Principal Components.

\begin{tabular}{llllllll}
\hline Variable & Comp1 & Comp2 & Comp3 & Comp4 & Comp5 & Comp6 & Comp7 \\
\hline Net Investment & -0.4232 & 0.0779 & 0.0732 & -0.0414 & -0.0368 & 0.8755 & -0.1997 \\
Employment & -0.2251 & 0.8245 & 0.3877 & -0.0306 & 0.2738 & -0.181 & 0.103 \\
Electricity & 0.4003 & 0.1221 & -0.4181 & -0.4111 & 0.6151 & 0.2651 & 0.1802 \\
LGDPC & 0.398 & 0.2947 & -0.1249 & 0.5544 & -0.3075 & 0.3029 & 0.4955 \\
LFA & 0.3455 & -0.3463 & 0.7946 & 0.004 & 0.2576 & 0.1819 & 0.1729 \\
C02emission & 0.4176 & 0.1764 & 0.0024 & 0.3849 & 0.1684 & 0.0321 & -0.7855 \\
Combustible & -0.3973 & -0.2477 & -0.1505 & 0.6106 & 0.5967 & -0.0677 & 0.157 \\
\hline
\end{tabular}

\subsection{Augmented Dickey Fuller Test}

The Table 4 presented below explains the results of the Augmented Dickey-Fuller (ADF) test which has been determined with the t-statistics and probability. In case of LFDI, the p-value is estimated at 0.055 which is more than 0.05 , therefore, the null hypothesis of the presence of unit root is accepted. This suggests that the data pertaining to the LFDI is non-stationary. In addition, the difference between LFDI which is denoted as $\mathrm{d}(\mathrm{LFDI})$ has $\mathrm{p}$-value of 0.000 which is less than 0.05 , therefore, the null hypothesis of the presence of unit root is rejected. This implies that the data for the difference in the LFDI is stationary. Furthermore, there is existence of unit root for IGF as the p-value is estimated at 0.653 which is greater than 0.05 hence the null hypothesis is accepted. This suggests that data of the study is non-stationary.

International Journal of Business Management and Finance Research Vol. 3, No. $1, p p .12-19$

2020

DOI: $10.53935 / 2641-5313 . v 3 i 1.39$ Email: Wang@gmail.com Funding: This study received no specific financial support.

Article History:

Received: 7 April 2020

Revised: 4 May 2020

Accepted: 20 May 2020

Published: 1 June 2020

() 2020 by the authors; licensee Academic

Publishing Group
Table-4. Unit root testing through ADF.

\begin{tabular}{lll}
\hline Augmented Dickey-Fuller test statistic & T-Statistics & Prob.* \\
\hline LFDI & -2.827 & 0.055 \\
d(LFDI) & -7.42 & 0.000 \\
IGG & -1.247 & 0.653 \\
D(IGG) & -6.743 & 0.000 \\
\hline
\end{tabular}




\subsection{Bound Testing}

Considering the ARDL bound test, it has been explained that the f-statistics was estimated at 1.763 where the value for t-statistics is based on -0.734 . The values are in line with the study of Pesaran, Shin, and Smith (2001) which suggests that the criteria for bound test is values is based on f-statistics and t-statistics (Table 5).

Table-5. Bound Critical Values.

\begin{tabular}{|c|c|c|c|c|c|c|}
\hline & \multirow{2}{*}{$\begin{array}{l}10 \% \\
\text { I(0) }\end{array}$} & \multicolumn{2}{|c|}{$5 \%$} & \multicolumn{3}{|c|}{$1 \%$} \\
\hline & & I(1) & $\mathbf{I}(\mathbf{0})$ & $\mathbf{I}(\mathbf{1})$ & $\mathbf{I}(\mathbf{0})$ & $\mathbf{I}(\mathbf{1})$ \\
\hline $\mathrm{F}$ & 1.763 & 2.44 & 3.15 & 4.11 & 3.28 & 3.88 \\
\hline $\mathrm{T}$ & -0.734 & -3.88 & 4.93 & 4.81 & 6.02 & 4.92 \\
\hline
\end{tabular}

\subsection{Autoregressive Distributed Lag (ARDL)}

Based on the findings of the unit root testing, the ARDL technique has been selected for presenting the analysis. Autoregressive distributed lag (ARDL) is considered as the most effective method for the evaluation of single-equation regression based on the time series data and does not require data to be stationary or the non-stationary as unit root has been identified in the previous section. One of the significant aspects for the ARDL is based on the fact that it includes the lagged values for the variables which includes the dependent and independent variable for strengthening the model and determination for the short-run or long-run relation of the variables. The results of the ARDL are reflected in the Table 6 presented below,

Table-6. Long Run Coefficients.

\begin{tabular}{|c|c|c|c|c|c|}
\hline & Variables & Coefficient & Std. Err. & t-statistics & Prob.* \\
\hline LR & Foreign Direct Investment (LFDI) & & & & \\
\hline $\begin{array}{l}\text { R-S } \\
\text { Sig }\end{array}$ & $\begin{array}{l}\text { L1. } \\
\text { red }=0.2039 \\
\text { cant at } 10 \% ; * * \text { Significant at } 5 \% ; * *\end{array}$ & $\begin{array}{l}0.57821 \\
\text { iificant at } 1 \%\end{array}$ & 0.816922 & 0.71 & 0.484 \\
\hline
\end{tabular}

As per the table- 6 presented above, it can be stated that the co-efficient of determination (R-Square) for the ARDL model is 0.203 or $20.3 \%$ which indicates that $20.3 \%$ variance for the inclusive green growth can be predicted or evaluated with the foreign direct investment (LFDI). Meanwhile, considering the long-run influences, the inclusive green growth has p-value which is estimated at 0.468 which is above significance level of 5\% reflecting that ARDL model is not statistically significant and hence the results for the model could be highlighted as with the inclusion of certain errors. The estimation for the FDI with the IGG that is evaluated at the p-value of 0.484 which is greater than the significance level of $5 \%$. Therefore, it can be suggested that in the long-run, there is no relation between FDI and inclusive green growth.

\begin{tabular}{|c|c|c|c|c|c|}
\hline Variables & & Coefficient & Std. Err. & t-statistics & Prob.* \\
\hline SR & $\begin{array}{l}\text { Foreign Direct Investment } \\
\text { LFDI }\end{array}$ & & & & \\
\hline
\end{tabular}

However, based on the short-run results, it can be evaluated that FDI and IGG are related because the pvalue is estimated at 0.013 which is less than the significance level of $5 \%$. Hence, it can be stated that both FDI and IGG variable is found to have no significant effect in the long-run. However, there are significantly related in the short-run.

International Journal of Business Management and Finance Research Vol. 3, No. 1, pp. 12-19

2020

DOI: $10.53935 / 2641-5313 . v 3 i 1.39$

Email: Wang@gmail.com

Funding: This study received no specific

financial support.

Article History:

Received: 7 April 2020

Revised: 4 May 2020

Accepted: 20 May 2020

Published: 1 June 2020

(c) 2020 by the authors; licensee Academic Publishing Group

\section{Discussion}

The main aim of the study was based on whether the foreign direct investment improves inclusive green growth in case of empirical evidence from China. The inclusive green growth is considered as the sustainable development mode which is in pursuit of the economic growth, environmental protection and social equity. Initially, a gap was identified that limited number of researches has been carried out with regards to FDI and inclusive green growth. However, the research pertaining to inclusive growth is rather descriptive and hence 
this study constructs the evaluation in the China context which is related to inclusive growth index and analyses the influences of FDI with respect to inclusive green growth in the China. Therefore, for evaluating the impact of FDI on inclusive green growth, the IGG indices were calculated for which Principal Component Analysis (PCA) which has been later used as the independent variable. The data has been considered of the last 30 years with annual frequency. For the assessment of the association, the researcher has used Autoregressive Distributed Lag Model (ARDL) which is preceded by unit root testing. The findings of the study revealed that in long-run, there is no relation between FDI and inclusive green growth. However, based on the short-run results, it can be evaluated that FDI and IGG are related.

\section{Conclusion}

The aim of study was based on whether the foreign direct investments improve inclusive green growth in case of empirical evidence from China. After empirically testing the variables of the study, it was evaluated that in long-run, no association was identified between FDI and inclusive green growth. On the other hand, the short run results revealed significant association between FDI and inclusive green growth in the case of China. The paper still has some of the limitation because only China was used for the testing the variable. Therefore, the future research can be based on the selection number of countries in order to further authenticate the results.

\section{References}

Abdi, H., \& Williams, L. J. (2010). Principal component analysis. Wiley interdisciplinary reviews: Computational statistics, 2(4), 433-459.

Acosta, L. A., \& Suresh, S. (2016). Solar energy and inclusive green growth in India: A study of policy impacts on green employment generation in the private sector along the solar energy value chain. Case study prepared for Deutsche Gesellschaft für internationale Zusammenarbeit (GIZ) GmbH, German Development Institute/Deutsches Institut für Entwicklungspolitik (DIE) Page, 2(2).

Atewamba, C., \& Ngondjeb, D. Y. (2020). Inclusive green growth: Springer.

Berkhout, E., Bouma, J., Terzidis, N., \& Voors, M. (2018). Supporting local institutions for inclusive green growth: Developing an Evidence Gap Map. NJAS-Wageningen Journal of Life Sciences, 84, 51-71.

Chen, G., Yang, Z., \& Chen, S. (2020). Measurement and convergence analysis of inclusive green growth in the yangtze river economic belt cities. Sustainability, 12(6), 2356.Available at: https://doi.org/10.3390/su12062356

Cwele, F. (2019). Towards an Inclusive, green growth path: A review of South Africa's National Development Plan's approach to economic growth, (Doctoral dissertation, Stellenbosch: Stellenbosch University).

Eregha, P. B., \& Mesagan, E. P. (2017). The emergence of inclusive growth: Issues. Challenges and Policy Options for Nigeria.

Gu, J., Renwick, N., \& Xue, L. (2018). The BRICS and Africa's search for green growth, clean energy and sustainable development. Energy Policy, 120(C), 675-683.Available at: https://doi.org/10.1016/j.enpol.2018.05.028.

Jha, S., Sandhu, S. C., \& Wachirapunyanont, R. (2018). Inclusive green growth index: A new benchmark for quality of growth. Asian Development Bank.

Kurecic, P., \& Kokotovic, F. (2017). The relevance of political stability on FDI: A VAR analysis and ARDL models for selected small, developed, and instability threatened economies. Economies, 5(3), 22.Available at: https://doi.org/10.3390/economies5030022.

Narloch, U., Kozluk, T., \& Lloyd, A. (2016). Measuring inclusive green growth at the country level. Taking stock of measurement approaches and indicators. GGKP Research Committee on Measurement \& Indicators.

Nasir, M. A., Huynh, T. L. D., \& Tram, H. T. X. (2019). Role of financial development, economic growth \& foreign direct investment in driving climate change: A case of emerging ASEAN. Journal of Environmental Management, 242, 131-141.

Odhiambo, N. M. (2009). Energy consumption and economic growth nexus in Tanzania: An ARDL bounds testing approach. Energy Policy, 37(2), 617-622.

Ojha, V. P., Pohit, S., \& Ghosh, J. (2020). Recycling carbon tax for inclusive green growth: A CGE analysis of India. Energy Policy, 144, 111708 .Available at: https://doi.org/10.1016/j.enpol.2020.111708.

Pesaran, M. H., Shin, Y., \& Smith, R. J. (2001). Bounds testing approaches to the analysis of level relationships. Journal of applied econometrics, 16(3), 289-326.Available at: https://doi.org/10.1002/jae.616.

Sun, Y., Ding, W., Yang, Z., Yang, G., \& Du, J. (2020). Measuring China's regional inclusive green growth. Science of the Total Environment, $713,136367$.

International Journal of Business Management and Finance Research Vol. 3, No. 1, pp. 12-19

Tran, H. P. N. (2019). Linking inclusive green growth and the informal economy: Relationship between small-scale farming and informal vending in South Africa. Doctoral Dissertation, Massachusetts Institute of Technology.

World Bank. (2015). The case for inclusive green growth.

Zhu, S., \& Ye, A. (2018). Does foreign direct investment improve inclusive green growth? Empirical evidence from China. Economies, $6(3), 44$. 